Review Article

\title{
Homeobox Genes and Melatonin Synthesis: Regulatory Roles of the Cone-Rod Homeobox Transcription Factor in the Rodent Pineal Gland
}

\author{
Kristian Rohde, Morten Møller, and Martin Fredensborg Rath \\ Department of Neuroscience and Pharmacology, Faculty of Health and Medical Sciences, University of Copenhagen, \\ Rigshospitalet 6102, Blegdamsvej 9, 2100 Copenhagen, Denmark \\ Correspondence should be addressed to Kristian Rohde; rohde@sund.ku.dk
}

Received 26 January 2014; Accepted 7 April 2014; Published 30 April 2014

Academic Editor: Yoav Gothilf

Copyright (C) 2014 Kristian Rohde et al. This is an open access article distributed under the Creative Commons Attribution License, which permits unrestricted use, distribution, and reproduction in any medium, provided the original work is properly cited.

\begin{abstract}
Nocturnal synthesis of melatonin in the pineal gland is controlled by a circadian rhythm in arylalkylamine $\mathrm{N}$-acetyltransferase (AANAT) enzyme activity. In the rodent, Aanat gene expression displays a marked circadian rhythm; release of norepinephrine in the gland at night causes a cAMP-based induction of Aanat transcription. However, additional transcriptional control mechanisms exist. Homeobox genes, which are generally known to encode transcription factors controlling developmental processes, are also expressed in the mature rodent pineal gland. Among these, the cone-rod homeobox (CRX) transcription factor is believed to control pineal-specific Aanat expression. Based on recent advances in our understanding of $\mathrm{Cr} x$ in the rodent pineal gland, we here suggest that homeobox genes play a role in adult pineal physiology both by ensuring pineal-specific Aanat expression and by facilitating cAMP response element-based circadian melatonin production.
\end{abstract}

\section{Introduction}

Homeobox genes encode a large group of transcription factors involved in developmental processes throughout the animal kingdom [1]. The homeobox genes are molecularly characterized by the presence of a 180 -nucleotide sequence element, the homeobox, which encodes a 60-amino acid structural motif, the homeodomain. The homeodomain recognizes specific DNA binding sites and thereby enables the homeodomain proteins to function as transcription factors [2-6]. In the pineal gland, a number of homeobox genes control developmental processes. However, certain homeobox genes predominantly exert their function in mature pinealocytes [7]. Among these, the cone-rod homeobox (Crx) gene seems to play an important role in transcriptional regulation of arylalkylamine $\mathrm{N}$-acetyltransferase (Aanat) encoding the enzyme that controls the huge nocturnal peak in pineal melatonin synthesis [8].

In this paper, we review recent progress in our understanding of the biology of the CRX homeodomain transcription factor in the rodent pineal gland and propose a revised working model for the function of homeodomain transcription factors in regulation of rodent pineal Aanat transcription.

\section{Homeobox Genes Regulate Pineal Gland Development}

The mammalian pineal gland develops as a dorsal evagination from the most caudal part of the diencephalic roof [9]. As in other parts of the brain, timely and spatially controlled expression of a specific set of homeobox genes is essential for development of the pineal gland [7]. Gene knockout studies have identified a limited number of homeobox genes that are required for normal development of the rodent pineal gland; these include orthodenticle homeobox 2 (Otx2) [10], paired box 6 (Pax6) [11], brain specific homeobox (Bsx) [12], and LIM homeobox $9(\operatorname{Lh} x 9)$ [13]. In line with a role of this set of homeobox genes in the immature developing pinealocyte, that is, the principal melatonin-producing cell type of the pineal gland, in situ hybridization analyses have revealed that these homeobox genes are highly expressed during early stages in rodent pineal gland development before the 


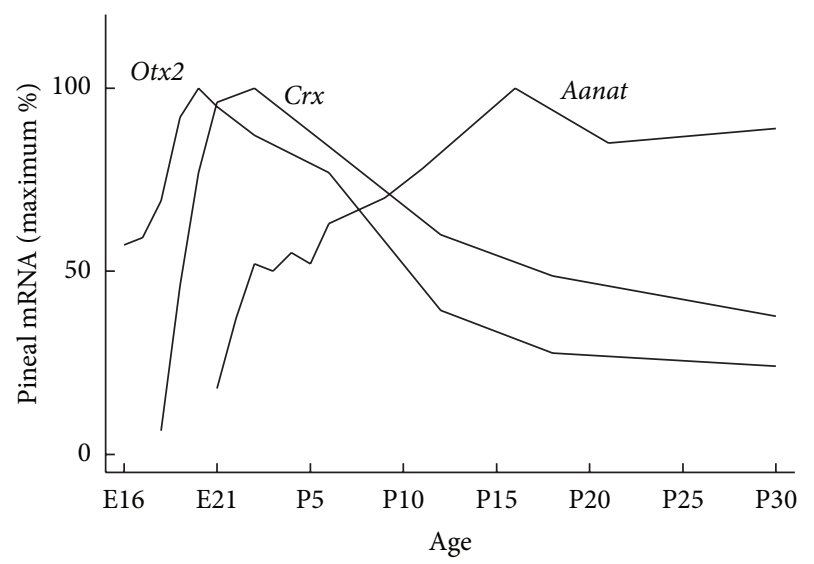

Figure 1: Appearance of Otx2, Crx , and Aanat transcripts in the developing rat pineal gland. Otx2 and Crx expression peak around birth [14], at which time Aanat expression is initiated [19]. The spatial and temporal correlation between peaks in expression of Otx2 and Crx and the start of Aanat expression supports that the OTX2 and CRX homeodomain transcription factors induce Aanat transcription [7]. E, embryonic day; P, postnatal day.

appearance of pineal melatonin synthesis [13-17]. However, pineal expression of homeobox genes is not restricted to prenatal stages (Figure 1); expression of homeobox genes involved in pineal development may persist into adulthood (e.g., Otx2) [14], expression may start at perinatal stages just prior to the onset of melatonin synthesis (e.g., Crx and retina and anterior neural fold homeobox $($ Rax $)$ ) [14, 18], or expression levels may start to increase even after or concomitant with the ontogenetic onset of melatonin synthesis (e.g., Pax4 and $L h \times 4$ ) [13, 15]. Thus, another set of homeobox genes, including $C r x$, predominantly exert their function in the mature melatonin-producing pinealocyte.

\section{Circadian Regulation of Melatonin Synthesis in the Mammalian Pineal Gland}

The mammalian melatonin rhythm generating system transforms the ambient lighting conditions into the internal hormonal message of melatonin, which is restricted to night time. The system is comprised of three parts: the suprachiasmatic nucleus (SCN) of the hypothalamus, the retina, and the pineal gland [20] as opposed to the melatonin rhythm generating system in nonmammalian vertebrate species, in which the three elements are integrated into one cell [21] (see below). The SCN of mammals generates a circadian rhythm. This rhythm is established by a cellular clock mechanism that comprises interacting transcriptional feedback loops [22]. The clock mechanism of the SCN is then synchronized with the successions of day and night via specific retinal photoreceptors projecting light information to the SCN via the retinohypothalamic tract [23]. Interestingly, a subset of retinal ganglion cells contains the photopigment melanopsin, which equips the cells with light-sensing properties. These irradiance detectors integrate their information on the surrounding lighting condition with signals from rod and cone photoreceptors to photoentrain the endogenous rhythm of the SCN [24]. The circadian clock of the SCN controls the pineal gland through a multisynaptic pathway [25]. The last neuron in the pathway, which has its soma situated in the superior cervical ganglion of the sympathetic nervous system, releases norepinephrine (NE) in the perivascular spaces of the pineal gland at night. NE binds to adrenergic receptors on the membrane of the pinealocyte and activates intracellular signaling pathways; this results in nocturnal melatonin synthesis $[20,26]$.

The enzymes AANAT and acetylserotonin O-methyltransferase (ASMT) catalyze the conversion of serotonin to melatonin. Nocturnal increase in AANAT enzymatic activity, as a result of $\mathrm{NE}$ release, determines the circadian melatonin production of the pineal gland. In the rodent, a marked nightly increase of Aanat transcription and posttranslational modifications of the AANAT protein account for the increase in AANAT enzymatic activity $[8,27,28]$. In other mammalian species, the dynamics of the AANAT enzymatic activity is effectuated through mechanisms other than transcriptional regulation of the Aanat gene. For instance, in sheep, monkey, and human, pineal Aanat transcript levels do not oscillate on a circadian basis. However, in all mammalian species, the rhythm of pineal gland melatonin production is reliant on the nocturnal release of NE in the gland [29-31]. In the rodent, the release of NE from the sympathetic nerve endings binds and activates adrenergic receptors on the pinealocyte, which results in an increased intracellular cAMP level. cAMP-activated protein kinase A phosphorylates the cAMP response element binding protein (CREB), which binds cAMP responsive element (CRE) cis-regulatory elements in the Aanat promoter and induces transcription [32, 33]. Thus, in the rodent, transcriptional regulation of Aanat is of special importance for melatonin to function as the hormonal messenger of darkness.

Because cAMP does not elevate the level of Aanat mRNA in cells other than the pinealocytes and to some extent retinal photoreceptors [34] (see below), additional regulatory mechanisms of Aanat expression must exist. These are thought to play a permissive or regulatory role in ensuring tissuespecific Aanat expression in addition to the cAMP/CREbased transcriptional control [7, 35]. As mentioned above, several homeobox genes have been shown to be expressed in the developing and adult pineal gland of the rodent and some have also been shown to bind photoreceptor conserved elements (PCEs) that are present in the Aanat promoter region and to influence Aanat transcription.

\section{Local Control of Aanat Rhythms in Photoreceptor Cells}

Melatonin is also synthesized in the mammalian retina [36, 37]. Whereas circadian biology of the mammalian pineal gland is controlled by the circadian clock of the SCN, the existence of an endogenous circadian clock within the mammalian retina is evident from the persistence of the retinal melatonin rhythm in cultured retinae [38] and SCN-lesioned rats [39]. The endogenous retinal pacemaker appears to be located in photoreceptor cells [40]. 
Retinal Aanat expression is also present in photoreceptors $[41,42]$ and exhibits a day-night rhythm [43]. Contrary to the regulation of Aanat in the pineal gland, retinal Aanat transcription is driven directly by clock gene products; that is, the dimer consisting of circadian locomotor output cycles kaput (CLOCK) and aryl hydrocarbon receptor nuclear translocator-like (ARNTL), which are encoded by core clock genes, binds directly to cis-regulatory elements, so-called E-boxes, in the Aanat promoter to drive circadian gene expression $[44,45]$. As reviewed below, a set of homeobox genes predominantly expressed in the pinealocyte and the retinal photoreceptor seems to control tissue-specific Aanat expression; however, certain E-box sequences have also been shown to confer tissue specificity presumably by silencing ectopic Aanat expression [46]. Retinal melatonin appears to play a paracrine role in dark-adaptation processes [34] and retinal AANAT further acts to counteract light-induced retinal degeneration [47].

A close relationship between photoreception and melatonin synthesis is also seen in pineal organs of nonmammalian vertebrates, which contain cells endowed with lightsensing properties $[48,49]$, an endogenous circadian clock [50-52], and nocturnal melatonin production guided by daily oscillations in AANAT activity $[53,54]$. From an evolutionary point of view, a common ancestral photoreceptor cell appears to have evolved into the retinal photoreceptor of the lateral eyes and the pinealocyte of the mammalian pineal gland $[55,56]$ which presently share both nocturnal melatonin production and the molecular characteristic of expression of a common set of homeobox genes, including Crx.

\section{Crx Expression in the Rodent Pineal Gland}

The Crx gene is expressed specifically in the photoreceptors of the retina and the pinealocytes of the pineal gland in the adult rodent [7, 14, 57-59]. During development, Crx is expressed in the rat pineal gland from embryonic day (E) 18 onwards with a peak around birth (Figure 1), suggesting that the role of Crx is not at the earliest of pineal gland developmental stages, but rather later on when the pinealocytes become differentiated [14]. Around the same embryonic stage, Crx expression has been reported in rat retinal photoreceptor cells [57]. Therefore, Crx seems to be important when differentiation processes occur in both photoreceptors and pinealocytes. Otx2 is expressed in the fore- and midbrain regions in the developing central nervous system. The total Otx2knockout mouse lacks the forebrain and midbrain regions at embryonic developmental stages. However, in a mouse with conditional Ot $x 2$ gene knockout specifically in the developing photoreceptors and pinealocytes, it has been shown that Otx2 is essential for development of retinal photoreceptors and pinealocytes [10, 60, 61]. Further, OTX2 transactivates Crx expression [10] and this is in accord with the timing of the developmental peak of Otx2 in both photoreceptors and pinealocytes, which precedes that of Crx (Figure 1) [14, 57].

Expression of Aanat and Asmt in the developing rat pineal gland starts around birth $[19,62]$. Interestingly, several homeobox genes display a pineal expression peak around the appearance of Aanat and Asmt and expression persists into adulthood, suggesting that these homeodomain transcription factors are important for inducing expression of the enzymes required for melatonin synthesis and thereby ensuring a pineal-specific circadian melatonin output (Figure 1). Persistent ontogenetic expression of pineal homeobox genes is seen in the case of Otx2 and Crx (Figure 2) [14], as well as $\operatorname{Rax}[18,63]$. The first Rax gene expression is confined to the forebrain and midbrain region of the developing central nervous system, but later becomes progressively restricted to specific brain areas, including the pineal gland and neural retina $[64,65]$. Moreover, $\mathrm{RAX}$ protein also plays a role in the transcriptional regulation of the Otx2 gene through a newly discovered cis-regulatory enhancer region in the Otx2 gene that RAX is capable of transactivating in photoreceptor precursors [66]. Notably, this enhancer sequence is also active in the rodent pineal gland at postnatal stages [67]. On the contrary, a classical homeobox gene such as Pax6 that is widely expressed in the developing central nervous system and is required for a normal development of the pineal gland $[11,68]$ is nearly undetectable in the pineal gland of the adult rodent [15]. In the mouse retina, PAX6 is a suppressor of Crx expression during development, thereby preventing an onset of premature photoreceptor differentiation [69]. The concurrent decline of Pax6 expression and increase of $\mathrm{Crx}$ expression in developing rat pinealocytes may reflect a similar functional relationship between these two transcription factors, permitting CRX to exert its control over transcription of the melatonin synthesizing enzymes and pinealocyte differentiation [7]. Complete maturation of pineal physiology with circadian melatonin synthesis occurs in the second postnatal week, at the time when sympathetic innervation of the gland is established and the SCN is capable of exerting its circadian control of the pineal endocrine output $[7,70]$.

\section{Roles of CRX in the Rodent Pineal Gland}

Investigations in a $C r x$-knockout mouse have demonstrated a central role of $C r x$ in the developing rodent visual system. Elimination of Crx causes a lack of photoreceptor outer segments, a reduced expression of several photoreceptorspecific genes accompanied by a disturbed development, and phenotype of different neuronal populations in the primary visual cortex. Further, circadian entrainment is attenuated $[73,74]$; temperature and running diurnal rhythms display decreased robustness [75]. The morphology of the pineal gland appears normal [76]; however, the expression of pineal Aanat is reduced $[73,75,76]$.

The observed influence of Crx on expression of several photoreceptor- and pineal-specific genes is in accord with the presence of cis-regulatory PCEs in the promoter region of these genes, including the Aanat promoter [35]. In vitro studies have shown that the CRX protein binds PCEs and causes transactivation of reporter constructs [35, 58, 59, $77,78]$. Notably, the promoter of the neural retina leucine zipper $(\mathrm{Nrl})$ gene, which is a basic-leucine zipper (bZIP) transcription factor [79], drives tissue-specific expression in rod photoreceptors and the pineal gland [80]. NRL and CRX have been shown to transactivate the rhodopsin promoter in a 


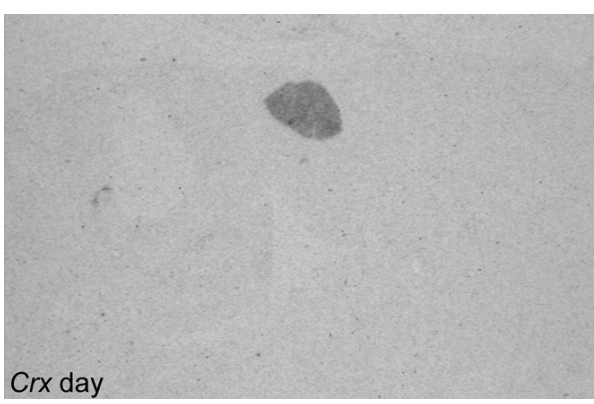

(a)

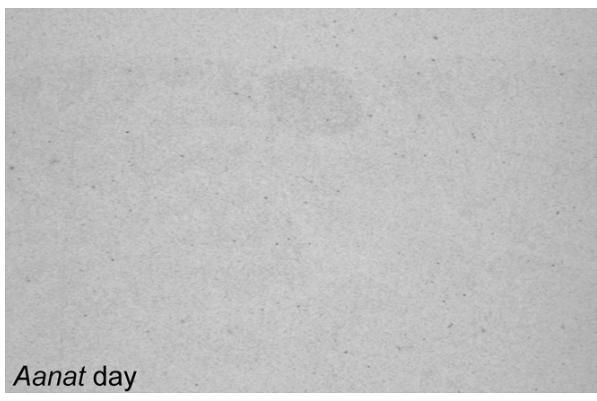

(c)

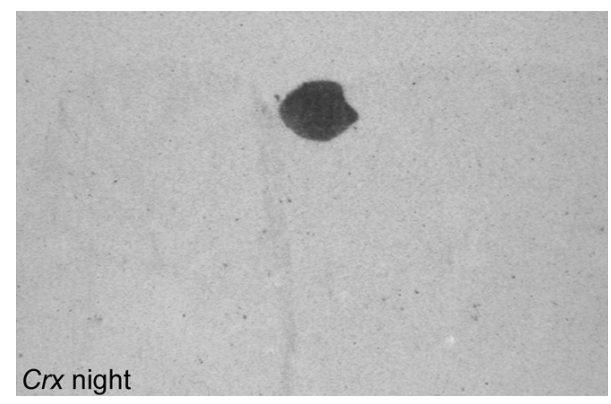

(b)

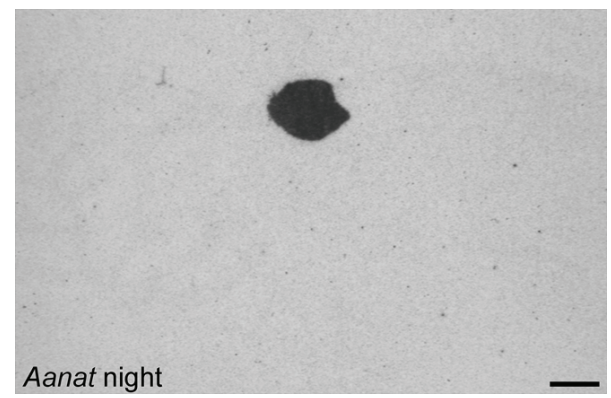

(d)

FIGURE 2: Crx and Aanat day/night expression in the adult rat pineal gland. Radiochemical in situ hybridization autoradiographs of midsagittal brain sections through the pineal gland of rats killed at daytime (Zeitgeber time 6) and nighttime (Zeitgeber time 18). Images are orientated with caudal to the left. Crx displays a specific expression in the pineal gland. Studies have shown a diurnal rhythm of Crx expression in the rat pineal gland with a night time peak [7, 35, 71]. Aanat also exhibits a pineal-specific expression; however, daytime transcript levels are very low. Scale bar, $1 \mathrm{~mm}$. Methodological details have been previously published [14, 71].

synergistic manner, and the rhodopsin gene is also expressed in the mammalian pineal gland [58, 81]. Thus, a similar cooperation between NRL and CRX is possible in the context of transcriptional regulation of Aanat, since both the Aanat and rhodopsin gene contain the PCE regulatory element in their promoter region [77]. In the adult rat pineal gland, many of the homeobox genes, which show a developmental expression peak around the time of the appearance of Aanat and Asmt expression, also display a diurnal rhythm of expression, that is, Rax, Otx2, and Crx [7, 18]. During the $24 \mathrm{~h}$ period, expression levels of these homeobox genes peak in a sequential manner before the late night expression peak of Aanat. That is, Rax peaks in the transition from day to night, Otx2 early in the night, and Crx in the middle of the night [7]. The daily expression profiles, existing data on binding of RAX, OTX2, and CRX homeodomain proteins to PCEs and the transactivating property of RAX on Otx2 transcription and of OTX2 on Crx transcription [10, 35, 58, $59,66,77,78,82]$, suggest that homeodomain proteins play a role in the expression of genes like Aanat that otherwise show a CRE-based circadian rhythm [32]. Thus, the occurrence of the Crx expression peaks a few hours before the peak of Aanat expression additionally supports the concept that homeodomain proteins act as regulatory factors of the daily expression profile of Aanat in the rodent pineal gland with CRX in a central position.

\section{Crx in the Retinal Photoreceptor and Nonmammalian Pinealocyte}

Photoreceptors are present in the retina of all vertebrates and in the pineal gland of most nonmammalian vertebrates [83]. In the retinal photoreceptor, $\mathrm{Cr} x$ is thought to be involved in the process of terminal differentiation of photoreceptors and is essential for formation of photoreceptor outer segments, as evidenced by gene knockout studies [73, 84]. At the molecular level, CRX is centrally placed in a network of transcription factors that regulate photoreceptor gene expression and thereby terminal differentiation of the various photoreceptor subtypes $[85,86]$. As in the rodent pineal gland, expression of Crx persists in the mature retina [14, 57-59], where CRX seems to positively control expression of a number of genes involved in phototransduction $[58,59,87,88]$. Many of these genes are also detectable in the mammalian pineal gland, reflecting the common phylogenetic relationship between the retinal photoreceptor and the pinealocyte.

In contrast to the mammalian pineal gland, the zebrafish pineal organ comprises cells that are capable of photodetection, which enable entrainment of the endogenously generated rhythm that controls circadian expression of genes in pinealocytes and hence the nocturnal synthesis of melatonin [89]. In zebrafish, the Otx5 gene, which is orthologous to the mammalian $\mathrm{Crx}$ gene, regulates genes that exhibit a circadian pattern of expression in the pineal complex. A lack 
of OTX5 protein attenuates the circadian pineal expression of Aanat2, which is the homolog of the mammalian Aanat gene and thus encodes the rate limiting enzyme in the zebrafish pineal production of melatonin [90]. Similar to the role of CRX in mammals, the action of OTX5 on Aanat2 in the zebrafish pineal organ is mediated through PCEs [77, 91, 92]. Interestingly, in the zebrafish pineal gland, OTX5, in addition to ensuring pineal-specific expression of Aanat2, is also capable of facilitating the circadian expression of Aanat2, which, in accordance with the situation in the mammalian retina, is otherwise controlled by the circadian CLOCK/ARNTL-dimer [91].

Like the pinealocyte of the zebrafish, the chicken pinealocytes possess the capability of light perception [48]. It has been shown in chicken that CRX activates transcription of Asmt through the interaction with PCEs in the Asmt promoter region [93]. A similar relationship has been shown between chicken Asmt and OTX2 [94]. Thus, CRX and the related OTX2 seem to exert a highly conserved regulatory role in transcriptional regulation of the enzymes involved in melatonin synthesis between vertebrate species.

\section{A Proposed Model for Shaping the Daily Aanat Expression Profile}

By the use of adenovirus-mediated shRNA knockdown and overexpression of $\mathrm{Cr} x \mathrm{mRNA}$ in cultured rat pinealocytes and investigations performed in the $C r x$-knockout mouse, it has been shown that CRX induces Aanat transcription in the rodent. At the same time, CRX exhibits a circadian rhythm in the pineal gland driven by the nocturnal release of NE from sympathetic nerve endings in the gland (Rohde K, Rovsing L, Ho AK, Møller M, and Rath MF, in preparation). Based on these findings and existing data on Aanat transcription, we here propose an extended working model for the role of homeodomain transcription factors in generation of pineal specificity and circadian output (Figure 3 ). Thus, in addition to ensuring pineal specificity of Aanat expression, mammalian CRX may also facilitate daily changes in Aanat expression and therefore act to shape the daily profile of melatonin synthesis.

\section{Abbreviations}

Aanat: Arylalkylamine N-acetyltransferase

Arntl: Aryl hydrocarbon receptor nuclear translocator-like

Asmt: Acetylserotonin O-methyltransferase

$B s x$ : Brain specific homeobox

bZIP: Basic-leucine zipper

Clock: Circadian locomotor output cycles kaput

CRE: cAMP response element

CREB: cAMP response element binding protein

Crx: Cone-rod homeobox

E: Embryonic day

Lhx: LIM homeobox

NE: Norepinephrine

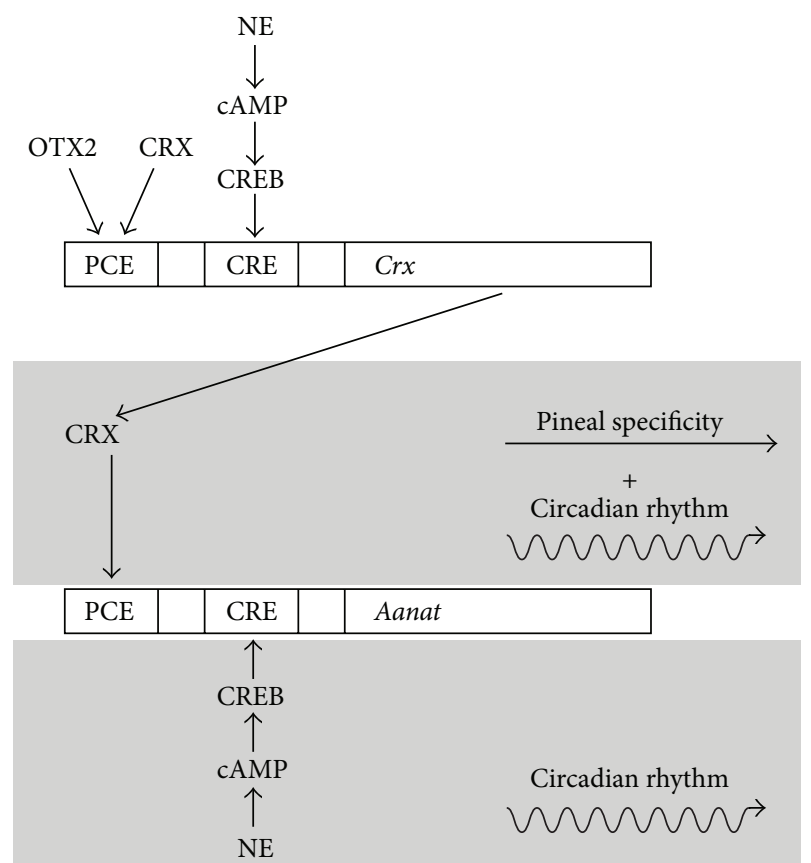

FIGURE 3: Working model of the role of homeobox genes in generation of pineal specificity and circadian output. CRX and OTX2 homeodomain transcription factors and NE/cAMP/CREB signaling, initiated by NE released from the sympathetic nerve endings at night, act on PCE and CRE cis-regulatory elements in the pineal Crx promoter region, respectively, to generate tissue-specific circadian expression of Crx. CRX protein acts on PCEs in the Aanat promoter region and confers a pineal-specific and circadian expression of Aanat. The homeodomain transcription factor generated rhythmicity of Aanat transcription supports the classical NE/cAMP/CREBdriven circadian rhythm of Aanat expression. The $\mathrm{Crx}$ promoter contains at least one PCE and several CRE cis-regulatory elements. In the Aanat promoter, several CREs and at least two PCEs exist. Promoter analysis was performed using Genomatix MatInspector software [72]. CRE, cAMP response element; CREB, cAMP response element binding protein; PCE, photoreceptor conserved element.

$N r l:$ Neural retina leucine zipper

Otx: Orthodenticle homeobox

P: Postnatal day

Pax: Paired box

PCE: Photoreceptor conserved element

Rax: Retina and anterior neural fold homeobox

SCN: Suprachiasmatic nucleus.

\section{Conflict of Interests}

The authors declare that there is no conflict of interests regarding the publication of this paper.

\section{Acknowledgments}

This work was supported by a Ph.D. scholarship from the Faculty of Health and Medical Sciences, University of Copenhagen (to KR), and the Lundbeck Foundation (Grant no. R83A8083 to MM and R108-A10301 to MFR). 


\section{References}

[1] M. Mallo and C. R. Alonso, "The regulation of Hox gene expression during animal development," Development, vol. 140, no. 19, pp. 3951-3963, 2013.

[2] W. J. Gehring, "The homeobox in perspective," Trends in Biochemical Sciences, vol. 17, no. 8, pp. 277-280, 1992.

[3] W. J. Gehring, M. Affolter, and T. Bürglin, "Homeodomain proteins," Annual Review of Biochemistry, vol. 63, pp. 487-526, 1994.

[4] W. McGinnis, C. P. Hart, W. J. Gehring, and F. H. Ruddle, "Molecular cloning and chromosome mapping of a mouse DNA sequence homologous to homeotic genes of Drosophila," Cell, vol. 38, no. 3, pp. 675-680, 1984.

[5] W. McGinnis, R. L. Garber, J. Wirz, A. Kuroiwa, and W. J. Gehring, "A homologous protein-coding sequence in drosophila homeotic genes and its conservation in other metazoans," Cell, vol. 37, no. 2, pp. 403-408, 1984.

[6] M. P. Scott and A. J. Weiner, "Structural relationships among genes that control development: sequence homology between the antennapedia, ultrabithorax, and fushi tarazu loci of Drosophila," Proceedings of the National Academy of Sciences of the United States of America, vol. 81, no. 13 I, pp. 4115-4119, 1984.

[7] M. F. Rath, K. Rohde, D. C. Klein, and M. Møller, "Homeobox genes in the rodent pineal gland: roles in development and phenotype maintenance," Neurochemical Research, vol. 38, no. 6, pp. 1100-1112, 2013.

[8] D. C. Klein, "Arylalkylamine N-acetyltransferase: 'the timezyme," Journal of Biological Chemistry, vol. 282, no. 7, pp. 4233-4237, 2007.

[9] J. Calvo and J. Boya, "Embryonic development of the rat pineal gland," Anatomical Record, vol. 200, no. 4, pp. 491-500, 1981.

[10] A. Nishida, A. Furukawa, C. Koike et al., "Otx2 homeobox gene controls retinal photoreceptor cell fate and pineal gland development," Nature Neuroscience, vol. 6, no. 12, pp. 1255-1263, 2003.

[11] G. Estivill-Torrús, T. Vitalis, P. Fernández-Llebrez, and D. J. Price, "The transcription factor Pax6 is required for development of the diencephalic dorsal midline secretory radial glia that form the subcommissural organ," Mechanisms of Development, vol. 109, no. 2, pp. 215-224, 2001.

[12] T. McArthur and A. Ohtoshi, "A brain-specific homeobox gene, Bsx, is essential for proper postnatal growth and nursing," Molecular and Cellular Biology, vol. 27, no. 14, pp. 5120-5127, 2007.

[13] F. Yamazaki, M. Møller, C. Fu et al., "The Lhx9 homeobox gene controls pineal gland development and prevents postnatal hydrocephalus," Brain Structure and Function, 2014.

[14] M. F. Rath, E. Muñoz, S. Ganguly et al., "Expression of the Otx2 homeobox gene in the developing mammalian brain: Embryonic and adult expression in the pineal gland," Journal of Neurochemistry, vol. 97, no. 2, pp. 556-566, 2006.

[15] M. F. Rath, M. J. Bailey, J.-S. Kim et al., "Developmental and diurnal dynamics of Pax4 expression in the mammalian pineal gland: Nocturnal down-regulation is mediated by adrenergiccyclic adenosine $3^{\prime}, 5^{\prime}$-monophosphate signaling," Endocrinology, vol. 150, no. 2, pp. 803-811, 2009.

[16] M. Cremona, E. Colombo, M. Andreazzoli, G. Cossu, and V. Broccoli, "Bsx, an evolutionary conserved Brain Specific homeoboX gene expressed in the septum, epiphysis, mammillary bodies and arcuate nucleus," Gene Expression Patterns, vol. 4, no. 1, pp. 47-51, 2004.
[17] D. C. Klein, M. A. A. Namboodiri, and D. A. Auerbach, "The melatonin rhythm generating system: developmental aspects," Life Sciences, vol. 28, no. 18, pp. 1975-1986, 1981.

[18] K. Rohde, D. C. Klein, M. Mãller, and M. F. Rath, "Rax: Developmental and daily expression patterns in the rat pineal gland and retina," Journal of Neurochemistry, vol. 118, no. 6, pp. 999-1007, 2011.

[19] M. Pfeffer and J. H. Stehle, "Ontogeny of a diurnal rhythm in arylalkylamine- $\mathrm{N}$-acetyltransferase mRNA in rat pineal gland," Neuroscience Letters, vol. 248, no. 3, pp. 163-166, 1998.

[20] D. C. Klein, M. J. Bailey, D. A. Carter et al., "Pineal function: Impact of microarray analysis," Molecular and Cellular Endocrinology, vol. 314, no. 2, pp. 170-183, 2010.

[21] J. Falcón, L. Besseau, M. Fuentès, S. Sauzet, E. Magnanou, and G. Boeuf, "Structural and functional evolution of the pineal melatonin system in vertebrates," Annals of the New York Academy of Sciences, vol. 1163, pp. 101-111, 2009.

[22] S. M. Reppert and D. R. Weaver, "Coordination of circadian timing in mammals," Nature, vol. 418, no. 6901, pp. 935-941, 2002.

[23] D. C. Klein and R. Y. Moore, "Pineal N-acetyltransferase and hydroxyindole-O-methyltransferase: control by the retinohypothalamic tract and the suprachiasmatic nucleus," Brain Research, vol. 174, no. 2, pp. 245-262, 1979.

[24] T. M. Schmidt, M. T. H. Do, D. Dacey, R. Lucas, S. Hattar, and A. Matynia, "Melanopsin-positive intrinsically photosensitive retinal ganglion cells: from form to function," Journal of $\mathrm{Neu}$ roscience, vol. 31, no. 45, pp. 16094-16101, 2011.

[25] M. Møller and F. M. Baeres, "The anatomy and innervation of the mammalian pineal gland," Cell and Tissue Research, vol. 309, no. 1, pp. 139-150, 2002.

[26] M. Møller, "Introduction to mammalian pineal innervation," Microscopy Research and Technique, vol. 46, pp. 235-238, 1999.

[27] P. H. Roseboom, S. L. Coon, R. Baler, S. K. Mccune, J. L. Weller, and D. C. Klein, "Melatonin synthesis: analysis of the more than 150 -fold nocturnal increase in serotonin $\mathrm{N}$ acetyltransferase messenger ribonucleic acid in the rat pineal gland," Endocrinology, vol. 137, no. 7, pp. 3033-3045, 1996.

[28] J. Borjigin, M. M. Wang, and S. H. Snyder, "Diurnal variation in mRNA encoding serotonin $\mathrm{N}$-acetyltransferase in pineal gland," Nature, vol. 378, no. 6559, pp. 783-785, 1995.

[29] J. D. Johnston, R. Bashforth, A. Diack, H. Andersson, G. A. Lincoln, and D. G. Hazlerigg, "Rhythmic melatonin secretion does not correlate with the expression of arylalkylamine $\mathrm{N}$ acetyltransferase, inducible cyclic AMP early repressor, Period1 or Cryptochromel mRNA in the sheep pineal," Neuroscience, vol. 124, no. 4, pp. 789-795, 2004.

[30] S. L. Coon, E. Del Olmo, W. Scott Young III, and D. C. Klein, "Melatonin synthesis enzymes in Macaca mulatta: Focus on arylalkylamine N-acetyltransferase (EC 2.3.1.87)," Journal of Clinical Endocrinology and Metabolism, vol. 87, no. 10, pp. 46994706, 2002.

[31] K. Ackermann, R. Bux, U. Rüb, H.-W. Korf, G. Kauert, and J. H. Stehle, "Characterization of human melatonin synthesis using autoptic pineal tissue," Endocrinology, vol. 147, no. 7, pp. 32353242, 2006.

[32] A. K. Ho and C. L. Chik, "Modulation of Aanat gene transcription in the rat pineal gland," Journal of Neurochemistry, vol. 112, no. 2, pp. 321-331, 2010.

[33] R. Baler, S. Covington, and D. C. Klein, "The rat arylalkylamine $\mathrm{N}$-acetyltransferase gene promoter. cAMP activation 
via a cAMP-responsive element-CCAAT complex," Journal of Biological Chemistry, vol. 272, no. 11, pp. 6979-6985, 1997.

[34] P. M. Iuvone, G. Tosini, N. Pozdeyev, R. Haque, D. C. Klein, and S. S. Chaurasia, "Circadian clocks, clock networks, arylalkylamine $\mathrm{N}$-acetyltransferase, and melatonin in the retina," Progress in Retinal and Eye Research, vol. 24, no. 4, pp. 433-456, 2005.

[35] X. Li, S. Chen, Q. Wang, D. J. Zack, S. H. Snyder, and J. Borjigin, "A pineal regulatory element (PIRE) mediates transactivation by the pineal/retina-specific transcription factor CRX," Proceedings of the National Academy of Sciences of the United States of America, vol. 95, no. 4, pp. 1876-1881, 1998.

[36] S. F. Pang, H. S. Yu, H. C. Suen, and G. M. Brown, "Melatonin in the retina of rats: a diurnal rhythm," Journal of Endocrinology, vol. 87, no. 1, pp. 89-93, 1980.

[37] G. Tosini, N. Pozdeyev, K. Sakamoto, and P. M. Iuvone, "The circadian clock system in the mammalian retina," BioEssays, vol. 30, no. 7, pp. 624-633, 2008.

[38] G. Tosini and M. Menaker, "Circadian rhythms in cultured mammalian retina," Science, vol. 272, no. 5260, pp. 419-421, 1996.

[39] K. Sakamoto, K. Oishi, M. Shiraishi et al., "Two circadian oscillatory mechanisms in the mammalian retina," NeuroReport, vol. 11, no. 18, pp. 3995-3997, 2000.

[40] G. Tosini, A. J. Davidson, C. Fukuhara, M. Kasamatsu, and O. Castanon-Cervantes, "Localization of a circadian clock in mammalian photoreceptors," The FASEB Journal, vol. 21, no. 14, pp. 3866-3871, 2007.

[41] T. Niki, T. Hamada, M. Ohtomi et al., "The localization of the site of arylalkylamine $\mathrm{N}$-acetyltransferase circadian expression in the photoreceptor cells of mammalian retina," Biochemical and Biophysical Research Communications, vol. 248, no. 1, pp. 115-120, 1998.

[42] C. Liu, C. Fukuhara, J. H. Wessel, P. M. Iuvone, and G. Tosini, "Localization of Aa-nat mRNA in the rat retina by flourescence in situ hybridization and laser capture microdissection," Cell and Tissue Research, vol. 315, no. 2, pp. 197-201, 2004.

[43] K. Sakamoto and N. Ishida, "Circadian expression of serotonin $\mathrm{N}$-acetyltransferase mRNA in the rat retina," Neuroscience Letters, vol. 245, no. 2, pp. 113-116, 1998.

[44] W. Chen and R. Baler, "The rat arylalkylamine Nacetyltransferase E-box: differential use in a master vs. a slave oscillator," Molecular Brain Research, vol. 81, no. 1-2, pp. 43-50, 2000.

[45] E. Muñoz, M. Brewer, and R. Baler, "Circadian transcription: thinking outside the E-Box," Journal of Biological Chemistry, vol. 277, no. 39, pp. 36009-36017, 2002.

[46] A. Humphries, T. Wells, R. Baler, D. C. Klein, and D. A. Carter, "Rodent Aanat: intronic E-box sequences control tissue specificity but not rhythmic expression in the pineal gland," Molecular and Cellular Endocrinology, vol. 270, no. 1-2, pp. 4349, 2007.

[47] J. Shen, K. Ghai, P. Sompol et al., "N-acetyl serotonin derivatives as potent neuroprotectants for retinas," Proceedings of the National Academy of Sciences of the United States of America, vol. 109, no. 9, pp. 3540-3545, 2012.

[48] T. Deguchi, "Rhodopsin-like photosensitivity of isolated chicken pineal gland," Nature, vol. 290, no. 5808, pp. 706-707, 1981.

[49] H. Meissl and P. Ekstrom, "Photoreceptor responses to light in the isolated pineal organ of the trout, Salmo gairdneri," Neuroscience, vol. 25, no. 3, pp. 1071-1076, 1988.
[50] S. A. Binkley, J. B. Riebman, and K. B. Reilly, "The pineal gland: a biological clock in vitro," Science, vol. 202, no. 4373, pp. 11981200, 1978.

[51] M. Menaker and S. Wisner, "Temperature-compensated circadian clock in the pineal of Anolis," Proceedings of the National Academy of Sciences of the United States of America, vol. 80, no. 19 I, pp. 6119-6121, 1983.

[52] J. Falcon, J. B. Marmillon, B. Claustrat, and J.-P. Collin, “Regulation of melatonin secretion in a photoreceptive pineal organ: an in vitro study in the pike," Journal of Neuroscience, vol. 9, no. 6, pp. 1943-1950, 1989.

[53] S. Binkley, J. B. Riebman, and K. B. Reilly, "Timekeeping by the pineal gland," Science, vol. 197, no. 4309, pp. 1181-1183, 1977.

[54] J. Falcon, J. F. Guerlotte, P. Voisin, and J.-P. H. Collin, "Rhythmic melatonin biosynthesis in a photoreceptive pineal organ: a study in the pike," Neuroendocrinology, vol. 45, no. 6, pp. 479-486, 1987.

[55] D. C. Klein, "The 2004 aschoff/pittendrigh lecture: Theory of the origin of the pineal gland-a tale of conflict and resolution," Journal of Biological Rhythms, vol. 19, no. 4, pp. 264-279, 2004.

[56] D. C. Klein, "Evolution of the vertebrate pineal gland: the AANAT hypothesis," Chronobiology International, vol. 23, no. 1-2, pp. 5-20, 2006.

[57] M. F. Rath, F. Morin, Q. Shi, D. C. Klein, and M. Møller, "Ontogenetic expression of the Otx2 and Crx homeobox genes in the retina of the rat," Experimental Eye Research, vol. 85, no. 1, pp. 65-73, 2007.

[58] S. Chen, Q. L. Wang, Z. Nie et al., "Crx, a novel Otxlike paired-homeodomain protein, binds to and transactivates photoreceptor cell-specific genes," Neuron, vol. 19, no. 5, pp. 1017-1030, 1997.

[59] T. Furukawa, E. M. Morrow, and C. L. Cepko, "Crx, a novel otxlike homeobox gene, shows photoreceptor-specific expression and regulates photoreceptor differentiation," Cell, vol. 91, no. 4, pp. 531-541, 1997.

[60] A. Simeone, D. Acampora, M. Gulisano, A. Stornaiuolo, and E. Boncinelli, "Nested expression domains of four homeobox genes in developing rostral brain," Nature, vol. 358, no. 6388, pp. 687-690, 1992.

[61] D. Acampora, S. Mazan, Y. Lallemand et al., "Forebrain and midbrain regions are deleted in Otx2-/- mutants due to a defective anterior neuroectoderm specification during gastrulation," Development, vol. 121, no. 10, pp. 3279-3290, 1995.

[62] C. Ribelayga, F. Gauer, P. Pévet, and V. Simonneaux, "Ontogenesis of hydroxyindole-O-methyltransferase gene expression and activity in the rat pineal gland," Developmental Brain Research, vol. 110, no. 2, pp. 235-239, 1998.

[63] C. H. Asbreuk, H. S. van Schaick, J. J. Cox, M. P. Smidt, and J. P. Burbach, "Survey for paired-like homeodomain gene expression in the hypothalamus: restricted expression patterns of Rx, Alx4 and goosecoid," Neuroscience, vol.114, no. 4, pp. 883889, 2002.

[64] P. H. Mathers, A. Grinberg, K. A. Mahon, and M. Jamrich, "The Rx homeobox gene is essential for vertebrate eye development," Nature, vol. 387, no. 6633, pp. 603-607, 1997.

[65] T. Furukawa, C. A. Kozak, and C. L. Cepko, "rax, a novel paired-type homeobox gene, shows expression in the anterior neural fold and developing retina," Proceedings of the National Academy of Sciences of the United States of America, vol. 94, no. 7, pp. 3088-3093, 1997. 
[66] Y. Muranishi, K. Terada, T. Inoue et al., "An essential role for RAX homeoprotein and NOTCH-HES signaling in Otx2 expression in embryonic retinal photoreceptor cell fate determination," Journal of Neuroscience, vol. 31, no. 46, pp. 16792-16807, 2011.

[67] Y. Muranishi, K. Terada, and T. Furukawa, "An essential role for Rax in retina and neuroendocrine system development," Development Growth and Differentiation, vol. 54, no. 3, pp. 341348, 2012.

[68] C. Walther and P. Gruss, "Pax-6, a murine paired box gene, is expressed in the developing CNS," Development, vol. 113, no. 4, pp. 1435-1449, 1991.

[69] V. Oron-Karni, C. Farhy, M. Elgart et al., "Dual requirement for Pax6 in retinal progenitor cells," Development, vol. 135, no. 24, pp. 4037-4047, 2008.

[70] R. Håkanson, M.-N. Lombard Des Gouttes, and C. Owman, "Activities of tryptophan hydroxylase, DOPA decarboxylase, and monoamine oxidase as correlated with the appearance of monoamines in developing rat pineal gland," Life Sciences, vol. 6, no. 24, pp. 2577-2585, 1967.

[71] M. J. Bailey, S. L. Coon, D. A. Carter et al., "Night/day changes in pineal expression of $>600$ genes: central role of adrenergic/cAMP signaling," Journal of Biological Chemistry, vol. 284, no. 12, pp. 7606-7622, 2009.

[72] K. Cartharius, K. Frech, K. Grote et al., "MatInspector and beyond: promoter analysis based on transcription factor binding sites," Bioinformatics, vol. 21, no. 13, pp. 2933-2942, 2005.

[73] T. Furukawa, E. M. Morrow, T. Li, F. C. Davis, and C. L. Cepko, "Retinopathy and attenuated circadian entrainment in Crxdeficient mice," Nature Genetics, vol. 23, no. 4, pp. 466-470, 1999.

[74] Y. Goldshmit, S. Galley, D. Foo, E. Sernagor, and J. A. Bourne, "Anatomical changes in the primary visual cortex of the congenitally blind Crx-/- mouse," Neuroscience, vol. 166, no. 3, pp. 886-898, 2010.

[75] L. Rovsing, M. F. Rath, C. Lund-Andersen, D. C. Klein, and M. Møller, "A neuroanatomical and physiological study of the nonimage forming visual system of the cone-rod homeobox gene (Crx) knock out mouse," Brain Research, vol. 1343, pp. 54-65, 2010.

[76] L. Rovsing, S. Clokie, D. M. Bustos et al., "Crx broadly modulates the pineal transcriptome," Journal of Neurochemistry, vol. 119, no. 2, pp. 262-274, 2011.

[77] L. Appelbaum and Y. Gothilf, "Mechanism of pineal-specific gene expression: the role of E-box and photoreceptor conserved elements," Molecular and Cellular Endocrinology, vol. 252, no. 12, pp. 27-33, 2006.

[78] A. Kimura, D. Singh, E. F. Wawrousek, M. Kikuchi, M. Nakamura, and T. Shinohara, "Both PCE-1/RX and OTX/CRX interactions are necessary for photoreceptor- specific gene expression," Journal of Biological Chemistry, vol. 275, no. 2, pp. 1152-1160, 2000.

[79] A. Swaroop, J. Xu, H. Pawar, A. Jackson, C. Skolnick, and N. Agarwal, "A conserved retina-specific gene encodes a basic motif/leucine zipper domain," Proceedings of the National Academy of Sciences of the United States of America, vol. 89, no. 1, pp. 266-270, 1992.

[80] M. Akimoto, H. Cheng, D. Zhu et al., "Targeting of GFP to newborn rods by $\mathrm{Nrl}$ promoter and temporal expression profiling of flow-sorted photoreceptors," Proceedings of the National Academy of Sciences of the United States of America, vol. 103, no. 10, pp. 3890-3895, 2006.
[81] S. Blackshaw and S. H. Snyder, "Developmental expression pattern of phototransduction components in mammalian pineal implies a light-sensing function," Journal of Neuroscience, vol. 17, no. 21, pp. 8074-8082, 1997.

[82] N. Bobola, P. Briata, C. Ilengo et al., "OTX2 homeodomain protein binds a DNA element necessary for interphotoreceptor retinoid binding protein gene expression," Mechanisms of Development, vol. 82, no. 1-2, pp. 165-169, 1999.

[83] H.-W. Korf, "Evolution of melatonin-producing pinealocytes," Advances in Experimental Medicine and Biology, vol. 460, pp. $17-29,1999$.

[84] A. Swaroop, D. Kim, and D. Forrest, “Transcriptional regulation of photoreceptor development and homeostasis in the mammalian retina," Nature Reviews Neuroscience, vol. 11, no. 8, pp. 563-576, 2010.

[85] A. K. Hennig, G.-H. Peng, and S. Chen, "Regulation of photoreceptor gene expression by Crx-associated transcription factor network," Brain Research, vol. 1192, pp. 114-133, 2008.

[86] J. C. Corbo, K. A. Lawrence, M. Karlstetter et al., "CRX ChIPseq reveals the cis-regulatory architecture of mouse photoreceptors," Genome Research, vol. 20, no. 11, pp. 1512-1525, 2010.

[87] F. J. Livesey, T. Furukawa, M. A. Steffen, G. M. Church, and C. L. Cepko, "Microarray analysis of the transcriptional network controlled by the photoreceptor homeobox gene Crx," Current Biology, vol. 10, no. 6, pp. 301-310, 2000.

[88] S. Blackshaw, R. E. Fraioli, T. Furukawa, and C. L. Cepko, "Comprehensive analysis of photoreceptor gene expression and the identification of candidate retinal disease genes," Cell, vol. 107, no. 5, pp. 579-589, 2001.

[89] H. W. Korf, C. Schomerus, and J. H. Stehle, "The pineal organ, its hormone melatonin, and the photoneuroendocrine system," Advances in Anatomy, Embryology, and Cell Biology, vol. 146, pp. $1-100,1998$.

[90] J. T. Gamse, Y. C. Shen, C. Thisse et al., "Otx5 regulates genes that show circadian expression in the zebrafish pineal complex," Nature Genetics, vol. 30, no. 1, pp. 117-121, 2002.

[91] L. Appelbaum, A. Anzulovich, R. Baler, and Y. Gothilf, "Homeobox-clock protein interaction in zebrafish: a shared mechanism for pineal-specific and circadian gene expression," Journal of Biological Chemistry, vol. 280, no. 12, pp. 11544-11551, 2005.

[92] L. Appelbaum, R. Toyama, I. B. Dawid, D. C. Klein, R. Baler, and Y. Gothilf, "Zebrafish serotonin-N-acetyltransferase-2 gene regulation: pineal-restrictive downstream module contains a functional E-box and three photoreceptor conserved elements," Molecular Endocrinology, vol. 18, no. 5, pp. 1210-1221, 2004.

[93] M. Bernard, V. Dinet, and P. Voisin, “Transcriptional regulation of the chicken hydroxyindole-O-methyltransferase gene by the cone-rod homeobox-containing protein," Journal of Neurochemistry, vol. 79, no. 2, pp. 248-257, 2001.

[94] V. Dinet, N. Girard-Naud, P. Voisin, and M. Bernard, "Melatoninergic differentiation of retinal photoreceptors: activation of the chicken hydroxyindole-O-methyltransferase promoter requires a homeodomain-binding element that interacts with Otx2," Experimental Eye Research, vol. 83, no. 2, pp. 276-290, 2006. 

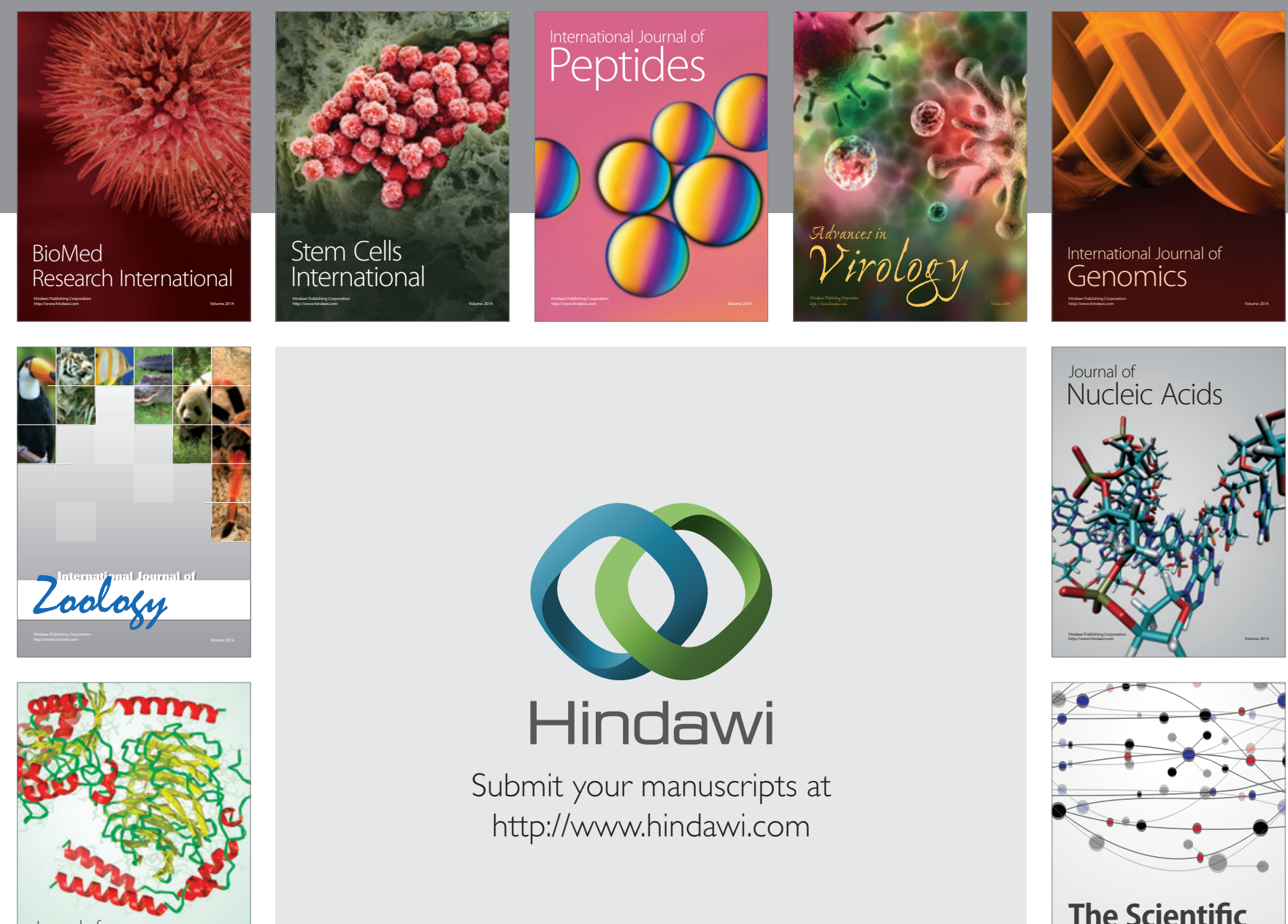

Submit your manuscripts at

http://www.hindawi.com

Journal of
Signal Transduction
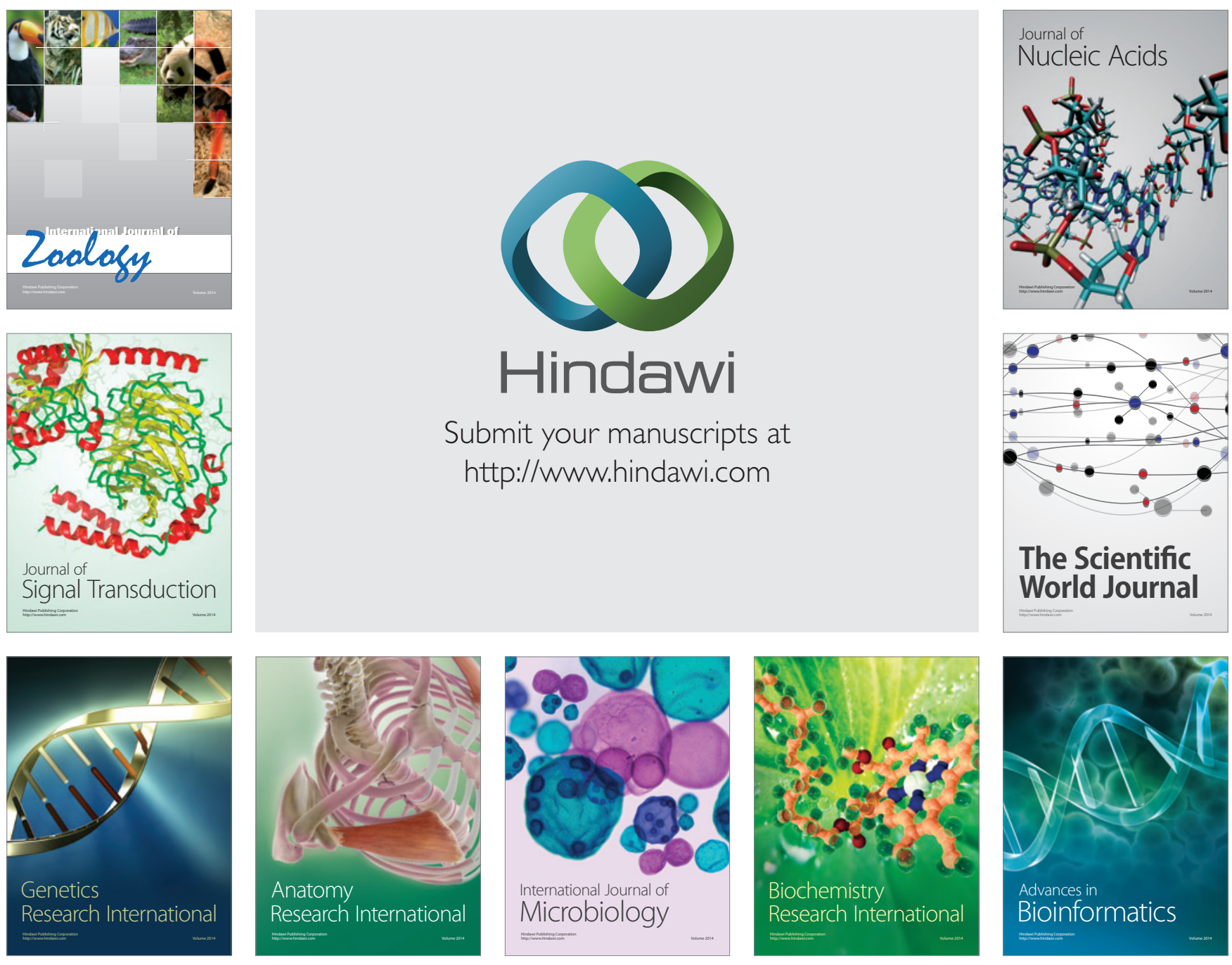

The Scientific World Journal
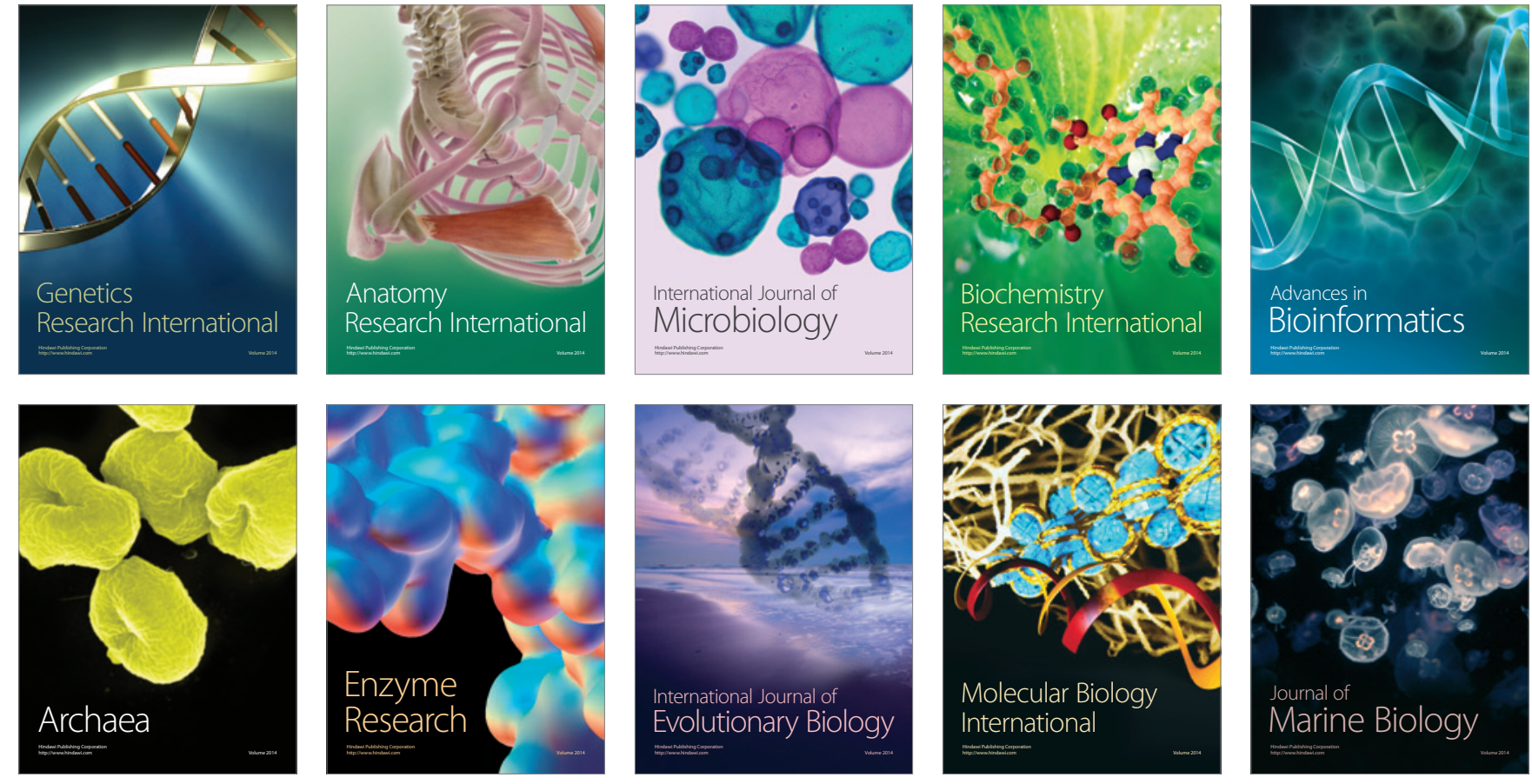